\title{
Oral Cyanocobalamin is Effective in the Treatment of Vitamin B12 Deficiency in Crohn's Disease
}

\author{
Fernando Gomollón 1,2,3,4,*,+, Carla J. Gargallo ${ }^{1,2,+}$, Jose Fernando Muñoz ${ }^{5}$, Raquel Vicente ${ }^{6}$, \\ Alberto Lue ${ }^{1,2}$, Alberto Mir ${ }^{7}$, Marta García-Alvarado ${ }^{8}$, Marta Gracia ${ }^{6}$ and Santiago García-López ${ }^{6}$ \\ 1 Hospital Clínico Universitario “Lozano Blesa”, Avenue San Juan Bosco, 15, Zaragoza 50009, Aragón, Spain; \\ carlajerusalen@hotmail.com (C.J.G.); alberto.lue@hotmail.com (A.L.) \\ 2 Aragón Health Research Institute (IIS Aragón), Zaragoza 50009, Aragón, Spain \\ 3 University of Zaragoza, Zaragoza 50009, Aragón, Spain \\ 4 Centro de Investigación Biomédica en Red, Enfermedades Hepáticas y Digestivas (CIBEREHD), \\ Madrid 28029, Spain \\ 5 Hospital Universitario de Salamanca, Salamanca 37007, Castilla y León, Spain; jmunozn@gmail.com \\ 6 Hospital Universitario Miguel Servet, Zaragoza 50009, Aragón, Spain; raquelvicentelidon@gmail.com (R.V.); \\ tagaru@hotmail.com (M.G.); sgarcia.lopez@gmail.com (S.G.-L.) \\ 7 Hospital Ernest Lluch Martin, Calatayud, Zaragoza 50299, Aragón, Spain; albertomirsubias@gmail.com \\ 8 Hospital Virgen de la Concha, Zamora 49022, Castilla y León, Spain; mery_271@hotmail.com \\ * Correspondence: fgomollon@gmail.com; Tel.: +34-976-765-700 \\ † Fernando Gomollón and Carla J. Gargallo is dual first authorship due to equal contribution.
}

Received: 18 January 2017; Accepted: 13 March 2017; Published: 20 March 2017

\begin{abstract}
Cobalamin deficiency is common in patients with Crohn's disease (CD). Intramuscular cobalamin continues to be the standard therapy for the deficiency and maintenance treatment in these patients, although oral route has been demonstrated to be effective in other pathologies with impaired absorption. Our aims were to evaluate the efficacy of oral therapy in the treatment of cobalamin deficiency and in long-term maintenance in patients with Crohn's disease. We performed a multicenter retrospective cohort study that included 94 patients with Crohn's disease and cobalamin deficiency. Seventy-six patients had B12 deficiency and $94.7 \%$ of them normalized their cobalamin levels with oral treatment. The most used dose was $1 \mathrm{mg} /$ day, but there were no significant differences in treatment effectiveness depending on the dose used ( $\geq 1 \mathrm{mg} / 24 \mathrm{~h}$ vs. $<1 \mathrm{mg} / 24 \mathrm{~h}$ ). Eighty-two patients had previous documented B12 deficiency and were treated with oral B12 to maintain their correct cobalamin levels. After a mean follow-up of 3 years, the oral route was effective as maintenance treatment in $81.7 \%$ of patients. A lack of treatment adherence was admitted by $46.6 \%$ of patients in who the oral route failed. In conclusion, our study shows that oral cyanocobalamin provides effective acute and maintenance treatment for vitamin B12 deficiency caused by $\mathrm{CD}$ with or without ileum resection.
\end{abstract}

Keywords: vitamin B12 deficiency; cobalamin deficiency; Crohn's disease; ileal resection; oral treatment; acute treatment; maintenance treatment

\section{Introduction}

Vitamin B12 (cobalamin) is a water-soluble vitamin that is essential for DNA synthesis, effective erythropoiesis, nervous system maintenance, and metabolism of protein, fat, and carbohydrate [1]. Humans cannot synthesize it, and hence need to obtain it through the diet, with it found almost exclusively in food of animal origin [2]. The manifestation of cobalamin deficiency ranges from subtle, non-specific clinical features to serious neurological and neuropsychiatric complications; because of that it is important to ensure an adequate intake and to provide a suitable screening for B12 deficiency in patients at risk [1]. A typical Western diet contributes 3-30 $\mu \mathrm{g}$ of B12 per day, of which 1-5 $\mu \mathrm{g}$ are 
absorbed, towards the recommended dietary allowance of 1 to $3 \mu \mathrm{g} /$ day. Also, the body storage is relatively high $(2000-5000 \mu \mathrm{g})$, which explains why clinical manifestations of B12 deficiency often appear late. Metabolism of this vitamin is complex and is made up of many processes, defects in any one of which can lead to deficiency [3].

Crohn's disease (CD) is a chronic inflammatory gastrointestinal disorder that can affect any segment of the gastrointestinal tract, including the terminal ileum, where most of the absorption (98\%) of B12 occurs. The reported prevalence of B12 deficiency in CD ranges from $5.6 \%$ to $38 \%$ and main causes of this deficiency are ileal resection and ileal disease (activity or fibrosis) [4-11].

The classical treatment for B12 deficiency is parenteral administration, in most countries intramuscular injection. However, a study performed in 1968 showed that $0.5 \%$ to $4 \%$ of radioactively labeled oral B12 can be absorbed along the entire intestine by passive diffusion in healthy people and in patients with pernicious anemia [12]. Although in normal conditions this may be a secondary mechanism, it may gain importance when the active mechanism mediated by intrinsic factor is affected. Several later randomized trials compared high oral doses (1000 to $2000 \mu \mathrm{g} /$ day) with parenteral administration in patients with pernicious anemia, atrophic gastritis, or ileum or gastric surgery have shown that high daily doses of oral B12 have similar or better short-term improvements in B12 levels and symptoms resolution than parenteral administration [13-15]. In patients with $C D$, oral therapy may be as effective as parenteral, but is currently underexplored. Therefore, the aims of our study are: (1) to evaluate the efficacy of oral therapy in the treatment of vitamin B12 deficiency in patients with Crohn's disease and (2) to analyze its efficacy in long-term maintenance treatment.

\section{Materials and Methods}

\subsection{Definition of Terminology}

The diagnosis of $\mathrm{CD}$ was performed in the patients included in our study according to the Lennard-Jones definition [16], which includes four groups of diagnosis criteria: clinical, radiological, endoscopic, and pathological criteria. The presence of at least two criteria is required and the pathology is the definitive one. Moreover, the sub-classification of Crohn's disease by phenotype was performed according to Montreal classification [17] that considered age of onset ( $A$; A1: below 16 years old, A2: between 17-40 years old, and A3: $>40$ years old), disease location ( $L$; L1: ileal, L2: colonic, L3: ileocolonic, and L4: isolated upper disease modifier), and disease behavior (B; B1: non-stricturing and non-penetrating, B2 stricturing, B3 penetrating, and p: perianal disease modifier) as the predominant phenotypic elements.

The diagnosis of B12 deficiency was defined according to local laboratory criteria as serum cobalamin $\leq 200 \mathrm{pg} / \mathrm{mL}$. Serum cobalamin concentrations were measured using chemiluminescence, with the assay from Beckman Coulter, which has a coefficient of variation $<12 \%$ and a very good correlation with radioimmunoassay $(r>0.95)$.

Finally, the diagnosis of anemia and macrocytosis were performed according to international standards and local laboratory criteria. In adults, anemia is defined as a hemoglobin $(\mathrm{Hb})$ levels below $12 \mathrm{gr} / \mathrm{dL}$ for non-pregnant women, $11 \mathrm{gr} / \mathrm{dL}$ for pregnant women, and $13 \mathrm{gr} / \mathrm{dL}$ for men [18] and macrocytosis is defined as the presence of macrocytes on a blood film, together with a raised mean corpuscular volume (MCV) (>98 fL) [18].

\subsection{Study Population}

This investigation is a cohort study with retrospective data collection conducted in four general hospitals integrated into the Spanish National Health System.

To address our aims, we distinguished two cohorts of patients: (1) patients with B12 deficiency and (2) patients with previous B12 deficiency who required maintenance treatment. Thus, to address our first aim, we included in our study patients attending our adult Inflammatory Bowel Disease Units diagnosed with CD and B12 deficiency who had been treated with B12 by oral route between January 2001 and November 2012. To address our second aim, we included patients attending our 
adult Inflammatory Bowel Disease Units diagnosed with CD and in who B12 deficiency was treated successfully with oral or intramuscular B12 between January 2001 and November 2012, but where maintenance treatment had then been conducted orally.

We included 94 patients with CD and B12 deficiency in our study, with a slight predominance of men. All patients were white and the average age of participants was $45 \pm 13$ years. Twenty-seven (28.7\%) patients were active smokers. In relation to characteristics of CD at diagnosis of our patients, and according to Montreal Classification, more than $95 \%$ of them had disease in the terminal ileum (L1 or L3). Two (2/94) patients also had upper gastrointestinal disease and 11 (11/94) also had perineal disease. Finally, a surgical resection of the ileum had been performed in 24 patients $(25.5 \%)$. Data about resection length were not available in all patients. Table 1 shows clinical and demographic characteristics of the study population.

Notably, none of the patients had neurological symptoms secondary to B12 deficiency. Also, none of the included patients had a previous diagnosis of pernicious anemia, and only one patient had prior history of gastric surgery.

Table 1. Clinical and demographic characteristics of the study population.

\begin{tabular}{cccc}
\hline Patients Demographics & $\begin{array}{c}\text { Overall Study Population } \\
\text { (94 Patients) } \boldsymbol{n} \mathbf{( \% )}\end{array}$ & $\begin{array}{c}\text { Cohort B12 Deficiency } \\
\text { Treatment (76 Patients) } \boldsymbol{n} \text { (\%) }\end{array}$ & $\begin{array}{c}\text { Cohort Maintenance } \\
\text { Treatment (82 Patients) } \boldsymbol{n} \text { (\%) }\end{array}$ \\
\hline Sex (male) & $52(55.3)$ & $42(55.3)$ & $45(54.9)$ \\
Age (years) & $45 \pm 13$ & $45 \pm 13$ & $44 \pm 13$ \\
Mean \pm standard deviation & $43,35-53$ & $42,35-54$ & $44,35-53$ \\
Median, interquartile range & $27(28.7)$ & $21(27.6)$ & $25(30.5)$ \\
Tobacco & $67(71.3)$ & $55(72.4)$ & $57(69.5)$ \\
Active smokers & & & \\
Non-active smokers & $4(4.3)$ & $2(2.6)$ & $4(4.9)$ \\
Montreal Classification & $65(69.1)$ & $52(68.4)$ & $56(68.3)$ \\
A1 & $25(26.6)$ & $22(28.9)$ & $22(26.8)$ \\
A2 & $45(47.9)$ & $37(48.7)$ & $40(48.8)$ \\
A3 & $4(4.2)$ & $4(5.3)$ & $3(3.7)$ \\
L1 & $45(47.9)$ & $35(46.0)$ & $39(47.5)$ \\
L2 & $36(38.3)$ & $29(38.1)$ & $31(37.8)$ \\
L3 & $41(43.6)$ & $35(46.1)$ & $35(42.7)$ \\
B1 & $17(18.1)$ & $12(15.8)$ & $16(19.5)$ \\
B2 & $11(11.7)$ & $2(2.6)$ & $11(13.4)$ \\
B3 & $2(1.88)$ & $1(1.31)$ & $2(2.43)$ \\
Perineal disease & $24(25.5)$ & $21(27.6)$ & $21(25.6)$ \\
Ileal resection & & &
\end{tabular}

\subsection{Therapeutic Regimens}

The different vitamin B12 oral treatment regimens used for treatment of B12 deficiency and for maintenance treatment are shown in Tables 2 and 3.

Table 2. Vitamin B12 oral treatment regimens used for treatment of B12 deficiency.

\begin{tabular}{|c|c|c|c|}
\hline Brand Name & Qualitative and Quantitative Composition & Dosage & Patients $n$ \\
\hline \multirow{3}{*}{ BENEXOLC } & \multirow{3}{*}{ B12 1 mg, B6 250 mg, B1 250 mg } & 1 tablet $/ 24 \mathrm{~h}$ & 38 \\
\hline & & 1 tablet $/ 12 \mathrm{~h}$ & 6 \\
\hline & & 1 tablet $/ 8 \mathrm{~h}$ & 3 \\
\hline FOLIDOCEC & B12 $0.002 \mathrm{mg}$, folic acid $0.4 \mathrm{mg}$ & 1 tablet $/ 12 \mathrm{~h}$ & 2 \\
\hline HIDROXIL@ & B12 0.5 mg, B6 250 mg, B1 $250 \mathrm{mg}$ & 1 tablet $/ 24 \mathrm{~h}$ & 1 \\
\hline NEURODAVUR@ & B12 2.5 mg, B6 $250 \mathrm{mg}$, B1 $250 \mathrm{mg}$ & 1 tablet $/ 24 \mathrm{~h}$ & 3 \\
\hline NEUROMADE@ & B12 1 mg, B6 50 mg, B1 50 mg & 1 tablet $/ 24 \mathrm{~h}$ & 6 \\
\hline \multirow{2}{*}{ OPTOVITEC } & \multirow{2}{*}{ B12 $1 \mathrm{mg}$} & 1 ampule $/ 24 \mathrm{~h}$ & 9 \\
\hline & & 2 ampule/7 days & 8 \\
\hline
\end{tabular}

Benexol@ (Bayer Hispania, Barcelona, Spain). Folidoce $\odot$ (Italfarmaco España, Madrid, Spain). Hidroxil@ (Almirall España, Barcelona, Spain). Neurdavur@ (Davur laboratorios, Madrid, Spain). Neuromade (Teofarma, Barcelona, Spain). Optovite $\odot$ (Normon, Madrid, Spain). 
Table 3. Vitamin B12 oral treatment regimens used for maintenance treatment.

\begin{tabular}{|c|c|c|c|}
\hline Brand Name & Qualitative and Quantitative Composition & Dosage & Patients $n$ \\
\hline \multirow{3}{*}{ BENEXOLC } & \multirow{3}{*}{ B12 1 mg, B6 250 mg, B1 $250 \mathrm{mg}$} & 1 tablet $/ 24 \mathrm{~h}$ & 22 \\
\hline & & 1 tablet $/ 48 \mathrm{~h}$ & 1 \\
\hline & & 2 tablet $/ 7$ days & 17 \\
\hline FOLIDOCE৫ & B12 $0.002 \mathrm{mg}$, folic acid $0.4 \mathrm{mg}$ & 1 tablet $/ 12 \mathrm{~h}$ & 2 \\
\hline NEURODAVUR@ & B12 2.5 mg, B6 250 mg, B1 250 mg & 1 tablet $/ 24 \mathrm{~h}$ & 8 \\
\hline NEUROMADE@ & B12 1 mg, B6 50 mg, B1 50 mg & 1 tablet $/ 24 \mathrm{~h}$ & 9 \\
\hline OPTOVITE৫) & B12 $1 \mathrm{mg}$ & 2 ampule $/ 7$ days & 23 \\
\hline
\end{tabular}

Benexol@ (Bayer Hispania, Barcelona, Spain). Folidoce $\odot$ (Italfarmaco España, Madrid, Spain). Neurdavur $\odot$ (Davur laboratorios, Madrid, Spain). Neuromade (Teofarma, Barcelona, Spain). Optovite $\odot$ (Normon, Madrid, Spain).

\subsection{Statistical Analysis}

An initial exploratory analysis of all clinical variables was carried out. Continuous variables were expressed as the mean and standard deviation or median and interquartile range; whereas, qualitative variables were expressed as frequencies and percentages. The relationship between qualitative variables was evaluated with the chi-square test or the Fisher exact test if the expected effective cases were less than 5. The student $t$-test or Mann-Whitney $U$ test was employed for comparing means of two independent groups. Normality was tested using the Kolmogorov-Smirnov test. For all tests, a two-sided $p$-value $<0.05$ was considered statistically significant. The statistical analyses were performed using SPSS software v22.0 for Windows.

\section{Results}

\subsection{Effectiveness of Oral Treatment in Vitamin B12 Deficiency}

Seventy-six patients of the overall population included (94 patients) had vitamin B12 deficiency and were treated with oral B12 therapy to correct their deficiency. In these patients, the mean serum cobalamin concentration before oral treatment was $152.83 \pm 34.09 \mathrm{pg} / \mathrm{mL}$ (median 157, interquartile range of $132-174.5 \mathrm{pg} / \mathrm{mL}$ ). Seventy-two $(94.7 \%)$ patients normalized their vitamin B12 levels $(>200 \mathrm{pg} / \mathrm{mL}$ ) after mean treatment duration of $193 \pm 278$ days (median 120, interquartile range 78-191). The mean serum cobalamin concentration after treatment increased to $398.14 \pm 208.90 \mathrm{pg} / \mathrm{mL}$ (median 354.59, interquartile range: 242 to 474.50). Figure 1 shows the evident change of B12 levels and Table 4 cobalamin levels of each patient before and after treatment. In relation to hematologic manifestations of B12 deficiency, before oral B12 treatment, 19.7\% (15) of patients had anemia (mean concentration of $\mathrm{Hb}: 13.61 \pm 1.67$ ), but no patient had macrocytic anemia. The erythrocyte MCV was elevated in $14(18.4 \%)$ patients, although without anemia, with a mean of MCV of $91.54 \pm 7.58$. After treatment with oral vitamin B12, there were no significant changes in $\mathrm{Hb}$ concentration nor in $\mathrm{MCV}$.

Folic acid levels $(\mathrm{ng} / \mathrm{mL})$, before and after treatment with oral cyanocobalamin, are shown in Supplementary Table 1 (Table S1).

In the subgroup of patients with ileal resection (21 patients), the mean serum cobalamin concentration before oral treatment was slightly lower than in patients without ileum surgery, but the differences were non-significant $(151.43 \pm 39.37 \mathrm{pg} / \mathrm{mL}$ vs. $153.36 \pm 3.23 \mathrm{pg} / \mathrm{mL}, p>0.05)$. Two of the four patients that did not normalize B12 levels after oral treatment had ileum resection. After oral B12 treatment, the mean serum cobalamin concentration increased significantly in patients with ileal resection and in patients without prior surgery $(368.38 \pm 189.45 \mathrm{pg} / \mathrm{mL}$ and $409.51 \pm 216.42 \mathrm{pg} / \mathrm{mL})$. There were no significant differences in the B12 levels reached between both groups.

Different oral treatment regimens were used; the daily dose of B12 used ranged from 0.004 to $3 \mathrm{mg}$, with $1 \mathrm{mg}$ daily being the most used dose (in 53 patients, 69.7\%). Fifty-nine patients $(77.6 \%)$ were treated with doses of oral B12 $\geq 1 \mathrm{mg} /$ day. There were no significant differences in oral treatment effectiveness in the normalization of B12 levels depending on the dose used $(\geq 1 \mathrm{mg} / 24 \mathrm{~h}$ vs. $<1 \mathrm{mg} / 24 \mathrm{~h} ; 94.9 \%$ vs. $94.1 \%, p>0.05)$. The different regimens used are shown in Table 2 . 
Table 4. Serum cobalamin levels $(\mathrm{pg} / \mathrm{mL})$ before and after acute treatment with oral cyanocobalamin.

\begin{tabular}{|c|c|c|c|c|c|c|c|c|c|c|c|c|c|c|c|c|c|c|c|c|c|c|c|c|c|c|c|c|c|c|c|c|c|c|c|c|c|c|}
\hline tient & 1 & 2 & 3 & 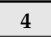 & 5 & 6 & 7 & 8 & 9 & 10 & $\overline{11}$ & 12 & 13 & 14 & 15 & 16 & 17 & 18 & 19 & 20 & 21 & 22 & 23 & 24 & 25 & 26 & 27 & 28 & 29 & 30 & 31 & 32 & 33 & 34 & 35 & 36 & 37 & 38 \\
\hline Before & 46 & 72 & 79 & 86 & 90 & 104 & 104 & 105 & 111 & 116 & 117 & 118 & 119 & 119 & 119 & 121 & 128 & 128 & 129 & 135 & 136 & 137 & 137 & 139 & 139 & 139 & 141 & 142 & 151 & 152 & 153 & 153 & 155 & 156 & 156 & 156 & 157 & 157 \\
\hline After & 177 & 229 & 554 & 333 & 464 & 488 & 273 & 232 & 202 & 230 & 02 & 1369 & 622 & 375 & 233 & 446 & 222 & 247 & 452 & 402 & 367 & 313 & 436 & 305 & 251 & 394 & 219 & 203 & 198 & 779 & 187 & 294 & 627 & 204 & 228 & 360 & 803 & 562 \\
\hline Patien & 39 & 40 & 41 & 42 & 43 & 4 & 45 & 46 & 47 & 48 & 49 & 50 & 51 & 52 & 53 & 54 & 55 & 56 & 57 & 58 & 59 & 60 & 61 & 62 & 63 & 64 & 65 & 66 & 67 & 68 & 69 & 70 & 71 & 72 & 73 & 74 & 75 & 76 \\
\hline Before & 15 & 159 & 159 & 161 & 163 & 164 & 16 & 166 & 168 & 169 & 170 & 170 & 170 & 171 & 17 & 173 & 173 & 17 & 17 & 175 & 175 & 176 & 177 & 181 & 184 & 186 & 192 & 193 & 196 & 199 & 200 & 200 & 200 & 200 & 200 & 200 & 200 & 200 \\
\hline After & 216 & 321 & 223 & 350 & 360 & 391 & 934 & 296 & 471 & 294 & 349 & 841 & 402 & 478 & 497 & 182 & 286 & 623 & 478 & 761 & 246 & 507 & 252 & 238 & 218 & 296 & 359 & 380 & 337 & 411 & 380 & 259 & 660 & 744 & 430 & 373 & 287 & 647 \\
\hline
\end{tabular}




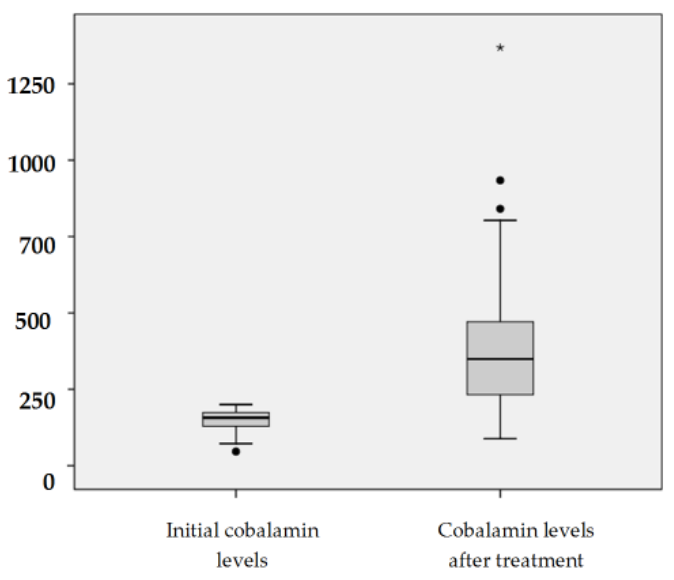

Figure 1. Serum cobalamin levels $(\mathrm{pg} / \mathrm{mL})$ before and after treatment with oral cyanocobalamin.

* Extreme value (1369 pg/mL).

\subsection{Effectiveness of Oral Route in Maintenance Treatment}

Eighty-two patients with CD and previous documented B12 deficiency were treated with oral B12 to maintain their correct cobalamin levels. Seventy-eight percent of them (64/82) had been previously treated with oral B12 to correct the deficiency and $22 \%(18 / 82)$ with intramuscular B12 treatment. The mean serum cobalamin concentration before oral maintenance treatment was $429.39 \pm 222.65 \mathrm{pg} / \mathrm{mL}$ (median 368, interquartile range of $273-489 \mathrm{pg} / \mathrm{mL}$ ). After a mean follow-up of $1091 \pm 841$ days (median 892, interquartile range 375-1765), the oral B12 route was effective to keep serum cobalamin levels $>200 \mathrm{pg} / \mathrm{mL}$ in $81.7 \%$ (67) of patients. The mean serum cobalamin concentration after follow-up was $364.45 \pm 226.62 \mathrm{pg} / \mathrm{mL}$ (median 298.5, interquartile range of 214-440 pg/mL). See Figure 2 and Table 5. Interestingly, a lack of oral B12 treatment adherence was admitted by almost half $(46.6 \%, 7 / 15)$ of the patients who failed to keep normal levels of cobalamin with the oral maintenance treatment.

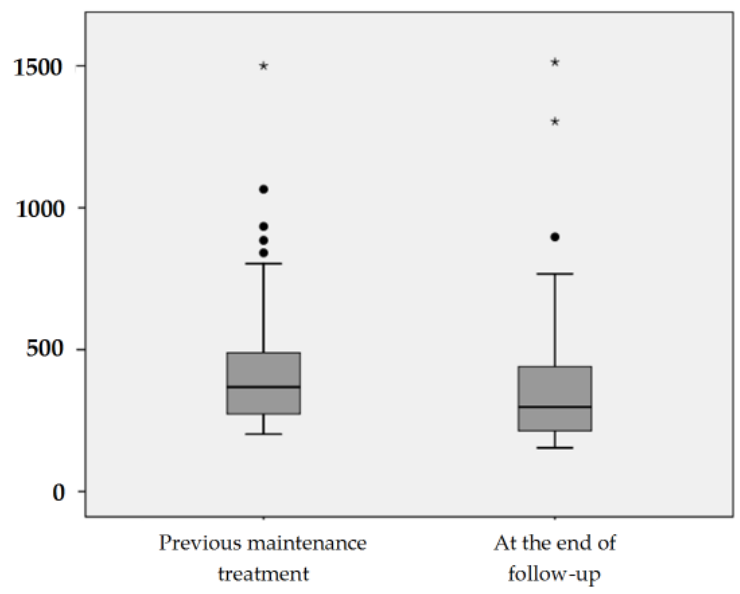

Figure 2. Serum cobalamin levels $(\mathrm{pg} / \mathrm{mL})$ during maintenance therapy; at the beginning of follow-up and at the end of follow-up. * Extreme values (1513 pg/mL, $1500 \mathrm{pg} / \mathrm{mL}$ and $1304 \mathrm{pg} / \mathrm{mL}$, see Table 5).

The daily dose of B12 used as maintenance treatment ranged from 0.004 to $2.5 \mathrm{mg}$, with $2 \mathrm{mg}$ weekly ( $0.28 \mathrm{mg} /$ day) being the most used dose (in 40 patients, $48.7 \%)$. There were no significant differences in oral maintenance treatment effectiveness depending on the dose used $(>0.28 \mathrm{mg} / 24 \mathrm{~h}$ vs. $\leq 0.28 \mathrm{mg} / 24 \mathrm{~h} ; 83.4 \%$ vs. $80 \%, p>0.05$ ). The different oral treatment regimens used are shown in Table 5. 
Table 5. Serum cobalamin levels $(\mathrm{pg} / \mathrm{mL})$ during maintenance therapy; at the beginning of follow-up and at the end of follow-up.

\begin{tabular}{|c|c|c|c|c|c|c|c|c|c|c|c|c|c|c|c|c|c|c|c|c|c|c|c|c|c|c|c|c|c|c|c|c|c|c|c|c|c|c|c|c|c|}
\hline Patient & 1 & 2 & 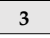 & 4 & 5 & 6 & 7 & 8 & 9 & 10 & 11 & 12 & 13 & 14 & 15 & 16 & 17 & 18 & 19 & 20 & 21 & 22 & 23 & 24 & 25 & 26 & 27 & 28 & 29 & 30 & & 32 & 33 & 34 & 35 & 36 & 37 & 38 & 39 & 40 & 41 \\
\hline nning & 202 & 202 & 202 & 204 & 214 & 216 & 218 & 222 & 223 & 228 & 229 & 230 & 232 & 238 & 244 & 246 & 247 & 251 & 252 & 259 & 27 & 286 & 287 & 294 & 294 & 96 & 296 & 304 & 305 & 305 & 313 & 321 & 337 & 338 & 34 & 350 & 359 & 360 & 360 & 364 & 367 \\
\hline & 168 & 255 & 155 & 271 & 214 & 422 & 211 & 295 & 310 & 193 & 2 & 224 & 289 & 491 & 288 & 209 & 413 & 263 & 176 & 174 & 303 & 279 & 287 & 294 & 194 & 463 & 372 & 359 & 233 & 166 & 186 & 176 & 283 & 316 & 454 & 293 & 359 & 468 & 270 & 364 & 215 \\
\hline Patient & 42 & 43 & 44 & 45 & 46 & 47 & 48 & 49 & 50 & 51 & 52 & 53 & 54 & 55 & 56 & 57 & 58 & 5 & 60 & 61 & 62 & 63 & 65 & 66 & 67 & 68 & 69 & 70 & 71 & 72 & 73 & 74 & 75 & 76 & 77 & 78 & 79 & 80 & 81 & 82 & \\
\hline eginnin & 369 & 371 & 373 & 375 & 380 & 380 & 389 & 391 & 394 & 402 & 411 & 430 & 432 & 436 & 446 & 452 & 464 & 471 & 478 & 488 & 489 & 497 & 532 & 554 & 560 & 587 & 622 & 623 & 645 & 647 & 660 & 695 & 744 & 761 & 803 & 841 & 885 & 934 & 1065 & 1500 & \\
\hline End & 897 & 173 & 177 & 214 & 302 & 239 & 290 & 154 & 354 & 409 & 600 & 524 & 387 & 496 & 1304 & 177 & 239 & 229 & 365 & 709 & 398 & 460 & 167 & 535 & 496 & 413 & 416 & 391 & 494 & 729 & 440 & 522 & 328 & 351 & 1513 & 167 & 214 & 616 & 217 & 767 & \\
\hline
\end{tabular}




\section{Discussion}

The traditional treatment of vitamin B12 deficiency is intramuscular injection, however, this vitamin may be offered orally. The increasing evidence that supports the use of oral vitamin B12 as an effective alternative to parenteral administration prompted the spread of oral administration in some countries, such as Sweden or Canada. However, in the rest of the world, intramuscular route remains the most used. Indeed, controversy still surrounds the advantages and effectiveness of the oral therapy [19]. Three randomized controlled trials (RCTs) have compared oral and intramuscular vitamin B12 in patients with B12 deficiency from different causes and, although relatively short in duration (<4 months) and of small sample size (158 patients in total), showed that oral was as effective as intramuscular therapy in normalizing B12 levels and hematological alterations [13-15]. We want to emphasize that two of these RCTs excluded patients with inflammatory bowel disease $[13,14]$ and the other included patients with CD, but the number was not shown in the publication [15]. Our large case series specifically evaluates oral administration route in CD and shows that oral cyanocobalamin provides effective acute and maintenance treatment for vitamin B12 deficiency caused by CD with or without ileum resection. Moreover, our follow-up periods are long, unlike previous studies. We found no significant changes in $\mathrm{Hb}$ concentration nor MCV after oral B12 therapy. It is important to note that, in our study, $20 \%$ of patients had anemia but none had macrocytic anemia, probably because most anemia was not attributable to B12 deficiency. In CD, cobalamin deficiency is rarely associated with anemia and most anemia is attributable to iron deficiency or chronic inflammation [5]. To our knowledge, there is a unique report that evaluated the efficacy of oral B12 replacement in CD. This study, which was published in 2014 in the "letters to the editor" section by Plener et al., concluded that 27 patients with low baseline values achieved normal serum B12 levels with oral B12 therapy and nine maintained them [20]. The data provided by authors are scarce. We want to note that, in 2013, we had presented the preliminary data for our study in the annual congress of Spanish Gastroenterology Association and also in Congress of European Crohn's and Colitis Organization. Therefore, we believe that our study was the first in evaluating oral B12 therapy in Crohn's disease patients [21,22].

In our opinion, it is necessary to know if oral treatment is effective in patients with CD. These patients may have significant portions of ileum affected by inflammation or resected and thus the active B12 absorption may have dramatically decreased and even passive absorption may be affected. Until now, most of the patients included in previous studies have had pernicious anemia, atrophic gastritis, gastric surgery, or low diet intake, ignoring patients with CD [13-15,23,24]. The possibility of taking an oral preparation would also allow patient preferences to be taken into account when deciding on what treatment to prescribe. Oral administration should provide patients with greater autonomy, improve treatment satisfaction, reduce treatment costs, and improve safety in anticoagulated patients [23,25-27]. Nyholm et al. showed that all patients included in their study found oral therapy to be acceptable or highly acceptable and that $87 \%$ preferred oral to intramuscular therapy [23]. A Canadian study of primary care found that 73\% of patients taking intramuscular B12 were willing to do a trial switch to oral route and after 6 months, $71 \%$ wished to remain on oral treatment permanently [25]. In relation to cost, there is little difference in the cost of oral versus intramuscular therapy when the medication alone is considered. However, intramuscular administration often involves a special trip to a health facility or a home visit by a health professional to administer the injection. Oral treatment could therefore save considerable Health Service resources. For example, a Canadian study [27] estimated that converting patients aged over 65 years on B12 replacement from the intramuscular to oral form could save between $\$ 2.9$ and $\$ 17.6$ million (2.5 and 15.3 million Euro) over five years in Ontario alone. In our public National Health System, B12 ampules are covered under all provincial health drug plans, while B12 tablets are not covered. Thus, oral B12 tablets probably save public Health Service resources, but are more expensive for Spanish patients. Because of that, one of the most used formulations in our study for maintenance treatment is B12 ampules, but by oral route. In our opinion, all advantages and disadvantages of both administration routes must 
be evaluated and explained to the patient. Although oral administration seems to be easy, effective, and less costly than the intramuscular route, some patients may benefit from traditional administration. For example, intramuscular therapy may be a better option to ensure timely administration in patients with non-adherence to oral medication. In our study, we detected that $8.5 \%$ of our patients in maintenance treatment had low-adherence, which resulted in treatment failure. This low adherence could be explained by some characteristics of our population related to low treatment adherence in patients with CD: a population that includes many young adults, many that take multiples drugs and with asymptomatic B12 deficiency [28]. Briefly, evaluating risk factors for low adherence to the different routes of administration is important before choosing one of them.

The oral dosage to be used in patients with CD is not yet to established. In the three RCTs that evaluate the oral therapy [11-13] and in most case series [20,23,24], high oral doses (1000-2000 $\mu \mathrm{g} /$ day) were used, but in these studies very few patients with $C D$ were included. Eussen et al. showed in their dose-finding trial that the lowest dose of oral vitamin B12 required to normalize mild deficiency in older people was more than 200 times greater than the recommended dietary intake ( $3 \mu \mathrm{g} /$ day) [29]. In view of the estimated $1 \%$ of total absorption by passive diffusion, a $1000 \mu \mathrm{g}$ daily dose is recommended in patients with pernicious anemia. However, patients with $C D$ and/or short ileal resection probably maintain, although not intact, a percentage of their active B12 absorption, and thus lower doses may be sufficient, especially in maintenance treatment. In our study, $2 \mathrm{mg}$ weekly ( $0.28 \mathrm{mg}$ daily) for maintenance treatment was the most used dosage (48.7\%) with high effectiveness. In fact, there were no significant differences between this dosage and other higher dosages. For treatment of the deficiency, we used high doses, with $1 \mathrm{mg}$ being the most used dose $(69.7 \%)$ but there were also no significant differences between this dosage and other lower dosages. Also, our patients had good tolerability without adverse events after high oral dose of vitamin B12.

Finally, the study's strengths include its large sample size and long follow-up period that allow for the evaluation of long-term efficacy. We also acknowledge several limitations. It is a retrospective study that did not includeB12 deficient patients with neurological symptoms. Also, functional biomarkers of the deficiency (methylmalonic acid and homocysteine concentrations) were not taken into account as diagnostic markers and outcome variables because these are not normally determined in our country, either at diagnosis or during follow-up.

\section{Conclusions}

To our knowledge, the present study represents the first study that specifically evaluated the role of oral administration route in the treatment of B12 deficiency in patients with CD, and also is one of the largest cohorts of patients with B12 deficiency treated orally. According to our results, oral administration of cyanocobalamin must be strongly considered and may be even the regimen of choice to treat B12 deficiency in CD. It is effective as a means in which to treat deficiency and also as a maintenance treatment, being well tolerated in these patients. Other studies are still required to test if oral B12 is suitable in patients with neurological symptoms. The oral dosage to be used in these patients is not yet fully established, but probably moderately high doses ( $1 \mathrm{mg} /$ day) are required for initial treatment and lower doses for maintenance treatment. A close monitoring with clinical review and repeat vitamin B12 levels may help to establish the most adequate maintenance doses. Patient preference is a factor of prime importance in the choice of administration route in order to avoid low treatment adherence. Finally, further research is needed to avoid perpetuating oral cyanocobalamin replacement as one of "medicine's best kept secrets" [30].

Supplementary Materials: The following are available online at http:/ /www.mdpi.com/2072-6643/9/3/308/s1, Table S1: Serum cobalamin levels $(\mathrm{pg} / \mathrm{mL})$ and folic acid levels $(\mathrm{ng} / \mathrm{mL})$ before and after acute treatment with oral cyanocobalamin.

Acknowledgments: To our patients, who continuously teach us so many things.

Author Contributions: Fernando Gomollón: Study concept and design; acquisition of data; analysis and interpretation of data; drafting of the manuscript and critical revision of the manuscript for important intellectual 
content. Carla J. Gargallo: Study concept and design; acquisition of data; analysis and interpretation of data; drafting of the manuscript and critical revision of the manuscript for important intellectual content. Fernando Muñoz: Study concept and design; acquisition of data. Raquel Vicente, Marta Gracía, and Marta García Alvarado: Acquisition of data. Alberto Lue and Alberto Mir: Acquisition of data and statistical analysis. Santiago García-Lopez: Study concept and design and critical revision of the manuscript for important intellectual content.

Conflicts of Interest: The authors declare no conflict of interest.

\section{References}

1. Stabler, S.P. Vitamin B12 deficiency. N. Engl. J. Med. 2013, 368, 2041-2042. [CrossRef] [PubMed]

2. Nielsen, M.J.; Rasmussen, M.R.; Andersen, C.B.; Nexø, E.; Moestrup, S.K. Vitamin B12 transport from food to the body's cells-A sophisticated, multistep pathway. Nat. Rev. Gastroenterol. Hepatol. 2012, 9, 345-354. [CrossRef] [PubMed]

3. Andrès, E. Oral cobalamin (vitamin B12) therapy in pernicious anemia. Autoimmun. Rev. 2014, $13,778$. [CrossRef] [PubMed]

4. Kulnigg, S.; Gasche, C. Systematic review: Managing anaemia in Crohn's disease. Aliment. Pharmacol. Ther. 2006, 24, 1507-1523. [CrossRef] [PubMed]

5. Battat, R.; Kopylov, U.; Szilagyi, A.; Saxena, A.; Rosenblatt, D.S.; Warner, M.; Bessissow, T.; Seidman, E.; Bitton, A. Vitamin B12 deficiency in inflammatory bowel disease: Prevalence, risk factors, evaluation, and management. Inflamm. Bowel Dis. 2014, 20, 1120-1128. [CrossRef] [PubMed]

6. Headstrom, P.D.; Rulyak, S.J.; Lee, S.D. Prevalence of and risk factors for vitamin B12 deficiency in patients with Crohn's disease. Inflamm. Bowel Dis. 2008, 14, 217-223. [CrossRef] [PubMed]

7. Yakut, M.; Ustün, Y.; Kabaçam, G.; Soykan, I. Serum vitamin B12 and folate status in patients with inflammatory bowel diseases. Eur. J. Intern. Med. 2010, 21, 320-323. [CrossRef] [PubMed]

8. Lambert, D.; Benhayoun, S.; Adjalla, C.; Gelot, M.A.; Renkes, P.; Felden, F.; Gerard, P.; Belleville, F.; Gaucher, P.; Guéant, J.L.; et al. Crohn's disease and vitamin B12 metabolism. Dig. Dis. Sci. 1996, 41, 1417-1422. [CrossRef] [PubMed]

9. Dyer, N.H.; Dawson, A.M. Malnutrition and malabsorption in Crohn's disease with reference to the effect of surgery. Br. J. Surg. 1973, 60, 134-140. [CrossRef] [PubMed]

10. Sinagra, E.; Tomasello, G.; Raimondo, D.; Rossi, F.; Facella, T.; Damiani, P.; Abruzzo, A.; Bruno, A.; Palumbo, V.D.; Cosentino, L.; et al. Nutrition, malnutrition and dietary interventions in inflammatory bowel disease. Prog. Nutr. 2014, 16, 79-89.

11. Altomare, R.; Damiano, G.; Abruzzo, A.; Palumbo, V.D.; Tomasello, G.; Buscemi, S.; Lo Monte, A.I. Enteral nutrition support to treat malnutrition in inflammatory bowel disease. Nutrients 2015, 7, 2125-2133. [CrossRef] [PubMed]

12. Berlin, H.; Berlin, R.; Brante, G. Oral treatment of pernicious anemia with high doses of vitamin B12 without intrinsic factor. Acta Med. Scand. 1968, 184, 247-258. [CrossRef] [PubMed]

13. Kuzminski, A.M.; del Giacco, E.J.; Allen, R.H.; Stabler, S.P.; Lindenbaum, J. Effective treatment of cobalamin deficiency with oral cobalamin. Blood 1998, 92, 1191-1198. [PubMed]

14. Bolaman, Z.; Kadikoylu, G.; Yukselen, V.; Yavasoglu, I.; Barutca, S.; Senturk, T. Oral versus intramuscular cobalamin treatment in megaloblastic anemia: A single-center, prospective, randomized, open-label study. Clin. Ther. 2003, 25, 3124-3134. [CrossRef]

15. Castelli, M.C.; Friedman, K.; Sherry, J.; Brazzillo, K.; Genoble, L.; Bhargava, P.; Riley, M.G. Comparing the efficacy and tolerability of a new daily oral vitamin B12 formulation and intermittent intramuscular vitamin B12 in normalizing low cobalamin levels: A randomized, open-label, parallel-group study. Clin. Ther. 2011, 33, 358-371. [CrossRef] [PubMed]

16. Lennard-Jones, J.E. Classification of inflammatory bowel disease. Scand. J. Gastroenterol. Suppl. 1989, 170, 2-6. [CrossRef] [PubMed]

17. Silverberg, M.S.; Satsangi, J.; Ahmad, T.; Arnott, I.D.; Bernstein, C.N.; Brant, S.R.; Caprilli, R.; Colombel, J.F.; Gasche, C.; Geboes, K.; et al. Toward an integrated clinical, molecular and serological classification of inflammatory bowel disease: Report of a Working Party of the 2005 Montreal World Congress of Gastroenterology. Can. J. Gastroenterol. 2005, 19, 5A-36A. [CrossRef] [PubMed] 
18. Cappellini, M.D.; Motta, I. Anemia in Clinical Practice-Definition and Classification: Does Hemoglobin Change With Aging? Semin. Hematol. 2015, 52, 261-269. [CrossRef] [PubMed]

19. Vidal-Alaball, J.; Butler, C.C.; Cannings-John, R.; Goringe, A.; Hood, K.; McCaddon, A.; McDowell, I.; Papaioannou, A. Oral vitamin B12 versus intramuscular vitamin B12 for vitamin B12 deficiency. Cochrane Database Syst. Rev. 2005. [CrossRef]

20. Plener, I.; Ferguson, C.; Kashkooli, S.; Saibil, F. Oral B12 replacement in Crohn's disease-Is B12 by injection obsolete? Aliment. Pharmacol. Ther. 2014, 40, 1365-1366. [CrossRef] [PubMed]

21. Mir, A.; Gracia, M.; García-Alvarado, M.; Lue, A.; Muñoz, F.; Garcia-Lopez, S.; Vicente, R.; Gomollon, F. Déficit de Vitamin B12 en la enfermedad de crohn: Tratamiento mediante suplementación oral. XVI Reunión Nacional de la Asociación Española de Gastroenterología. Madr. Spain Marzo 2013, 36, 165-170.

22. Mir, A.; Gracia, M.; García-Alvarado, M.; Lue, A.; Muñoz, F.; Garcia-Lopez, S.; Vicente, R.; Gomollon, F. Efficacy of Oral Supplementation in B12 Deficiency and Maintenance in Crohn's Disease. In Proceedings of the 8th Congress of ECCO (European Crohn's and Colitis Organization), Viena, Austria, 14-16 February 2013.

23. Nyholm, E.; Turpin, P.; Swain, D.; Cunningham, B.; Daly, S.; Nightingale, P.; Fegan, C. Oral vitamin B12 can change our practice. Postgrad. Med. J. 2003, 79, 218-220. [CrossRef] [PubMed]

24. Chan, C.Q.; Low, L.L.; Lee, K.H. Oral Vitamin B12 Replacement for the Treatment of Pernicious Anemia. Front. Med. (Lausanne) 2016, 3, 38. [CrossRef] [PubMed]

25. Kwong, J.C.; Carr, D.; Dhalla, I.A.; Tom-Kun, D.; Upshur, R.E. Oral vitamin B12 therapy in the primary care setting: A qualitative and quantitative study of patient perspectives. BMC Fam. Pract. 2005, 6, 8. [CrossRef] [PubMed]

26. Middleton, J.; Wells, W. Vitamin B12 injections: Considerable source of work for the district nurse. Br. Med. J. (Clin. Res. Ed.) 1985, 290, 1254-1255. [CrossRef]

27. Van Walraven, C.; Austin, P.; Naylor, C.D. Vitamin B12 injections versus oral supplements. How much money could be saved by switching from injections to pills? Can. Fam. Physician 2001, 47, 79-86. [PubMed]

28. Gomollón, F. Treatment adherence is always worse than we think: An unresolved problem in inflammatory bowel disease. Gastroenterol. Hepatol. 2016, 39, 14-19. [CrossRef]

29. Eussen, S.J.; de Groot, L.C.; Clarke, R.; Schneede, J.; Ueland, P.M.; Hoefnagels, W.H.; van Staveren, W.A. Oral cyanocobalamin supplementation in older people with vitamin B12 deficiency: A dose-finding trial. Arch. Intern. Med. 2005, 165, 1167-1172. [CrossRef] [PubMed]

30. Lederle, F.A. Oral cobalamin for pernicious anemia. Medicine's best kept secret? JAMA 1991, 265, 94-95. [CrossRef] [PubMed]

(C) 2017 by the authors. Licensee MDPI, Basel, Switzerland. This article is an open access article distributed under the terms and conditions of the Creative Commons Attribution (CC BY) license (http://creativecommons.org/licenses/by/4.0/). 